\title{
Evaluatie van multiprofessioneel onderwijs met behulp van de Readiness for Interprofessional Learning Scale (RIPLS)
}

\author{
C. Aubry, J. Goedhuys, R. Stroobants
}

\section{Samenvatting}

Inleiding: Multiprofessioneel onderwijs (MPO) kan een goede voorbereiding zijn op het werken in teams in de gezondheidszorg. Een vragenlijst om de houding ten aanzien van MPO te meten is geanalyseerd en toegepast bij het evalueren van een MPO-workshop. Het betrof een Nederlandse vertaling van de Readiness for Inter-Professional Learning Scale (RIPLS). Methode: De workshop werd bijgewoond door laatstejaarsstudenten van vijf zorgopleidingen in Vlaanderen: geneeskunde, verpleegkunde, maatschappelijk werk, kinesitherapie en ergotherapie. Voor en na de workshop hebben de studenten de RIPLS ingevuld en na de workshop ook een vragenlijst over de workshop. De interne consistentie van de RIPLS is nagegaan door middel van factoranalyse en de verschillen tussen de groepen studenten bij voor-en nameting zijn onderzocht met behulp van variantieanalyse.

Resultaten: De factoranalyse leverde twee schalen op met een interne consistentie van respectievelijk .80 en .60 (Cronbachs alfa): 'Effectiviteit als hulpverlener' en 'Professionele identiteit'. De score op de schaal 'Effectiviteit' steeg na de workshop. Er waren significante verschillen tussen groepen studenten in hun houding ten aanzien van MPO. De vragenlijst over de workshop toonde een positieve waardering.

Discussie: Vergelijking met de oorspronkelijke RIPLS leverde overeenkomsten en verschillen op. De betrouwbaarheid van de schaal professionele identiteit verschilde tussen voor-en nameting.

Conclusie en aanbevelingen: Een korte MPO-workshop leverde meetbare gunstige effecten op. Het zou interessant zijn de effecten van een langere cursus te onderzoeken. Hoewel de uitkomsten van de RIPLS bevestigd werden door een andere vragenlijst, is nader onderzoek naar de betrouwbaarheid gewenst. (Aubry C, Goedhuys J, Stroobants R. Evaluatie van multiprofessioneel onderwijs met behulp van de Readiness for Interprofessional Learning Scale (RIPLS). Tijdschrift voor Medisch Onderwijs 2003;21(3):106-114.)

\section{Inleiding}

In de gezondheidszorg wordt steeds meer samengewerkt tussen verschillende disciplines in de zorg rondom de patiënt. Ten onrechte wordt wel eens verondersteld dat deze samenwerking spontaan tot stand zal komen in het werkveld. Gray stelt: "It is hardly surprising that professionals who have been almost exclusively trained in isolation find it difficult to come to terms with sharing care when they finally emerge in practice" ${ }^{1}$ Een aan- tal factoren is belangrijk bij interprofessionele samenwerking. Om goed te kunnen samenwerken moeten de verschillende beroepsgroepen op de hoogte zijn van elkaars deskundigheden en rollen. Structurele en organisatorische factoren blijken de ontwikkeling naar teamwerk vaak te verhinderen. ${ }^{2}$ De attitude ten aanzien van de andere disciplines is daarbij eveneens erg bepalend. ${ }^{3}$

Om samenwerking te leren lijkt het van belang dat studenten de meerwaarde van 
samenwerking tussen verschillende disciplines al tijdens de opleiding ervaren. De professionele posities zijn op dat moment nog niet ingenomen en het concept van werken in een team, waar wederzijds begrip en respect centraal staan, kan een gunstige invloed hebben op het toekomstig functioneren in een team. ${ }^{4}$ Deze vorm van onderwijs wordt interprofessioneel of multiprofessioneel onderwijs (MPO) genoemd. Invoering van MPO blijkt niet altijd even gemakkelijk te zijn: docenten zijn niet altijd overtuigd van het nut, het vraagt heel wat organisatie om de uurroosters op elkaar af te stemmen en de menskracht ontbreekt. 5 In de medisch-onderwijskundige literatuur is een trend aanwezig naar Best Evidence Based Medical Education. ${ }^{6}$ Dat geldt natuurlijk ook voor MPO. Om MPO goed te kunnen evalueren zijn onder andere vragenlijsten nodig. Een van de vragenlijsten die hiervoor gebruikt zouden kunnen worden, is de 'Readiness for Interprofessional Learning Scale' (RIPLS). Deze lijst is ontwikkeld en op bruikbaarheid getest door Parsell en Bligh. ${ }^{7}$ Het leek ons van belang om deze vragenlijst te vertalen en te onderzoeken of de lijst ook in ons taalgebied en in onze cultuur bruikbaar is. Wij onderzochten de interne consistentie van de vragenlijst. Vervolgens is de lijst toegepast bij de evaluatie van een multiprofessionele workshop. In dit artikel wordt gerapporteerd over de betrouwbaarheid van de RIPLS en over de resultaten van een MPOworkshop gemeten met zowel de RIPLS als met een korte vragenlijst, die ingevuld zijn door studenten van vijf verschillende gezondheidszorgopleidingen in Vlaanderen.

\section{Methode}

\section{Instrumenten}

De 'Readiness for InterProfessional Learning Scale' (RIPLS) is ontwikkeld om ver- schillen in perceptie van studenten ten aanzien van MPO te meten. ${ }^{7}$ De oorspronkelijke RIPLS bestaat uit negentien uitspraken. De student geeft op een vijfpunts Likertschaal (1=helemaal niet akkoord tot 5 =helemaal akkoord) aan in hoeverre hij/zij het met een uitspraak eens is. Voor het onderzoek dat in dit artikel beschreven wordt, werden de uitspraken vertaald in het Nederlands en zowel taalkundig als inhoudelijk door experts nagekeken. Achteraf bleek dat bij de vertaling één item abusievelijk weggelaten was, waardoor de Nederlandstalige versie uit achttien items bestaat.

$\mathrm{Er}$ is nog een andere vragenlijst afgenomen om de workshop te evalueren. Deze vragenlijst bestond uit vijf uitspraken over de workshop waarop met ja of nee geantwoord moest worden (figuur 2).

\section{De onderzoekspopulatie}

De studenten geneeskunde in België die de specialisatie huisartsgeneeskunde kiezen, volgen een 'netwerkstage' van twee maanden om kennis te maken met de verschillende netwerken in de eerstelijnsgezondheidszorg. Er zijn onder andere stages bij apothekers, palliatieve zorgteams en schoolbegeleiding. Deze stage bood de mogelijkheid om studenten van verschillende opleidingen samen te brengen voor een multiprofessionele workshop.

In januari 2001 namen 281 studenten van vijf verschillende opleidingen (verpleegkunde, kinesitherapie, huisartsgeneeskunde, maatschappelijk werk en ergotherapie) deel aan deze workshop. Deze studenten is veertien dagen voor en direct na afloop van de workshop gevraagd de vertaalde RIPLS in te vullen. Na afloop werd de andere vragenlijst ook aan de studenten voorgelegd. Bij de voormeting waren de uitspraken van de RIPLS geformuleerd in de toekomende tijd en bij de 
nameting waren dezelfde uitspraken geformuleerd in de onvoltooid verleden tijd.

\section{De workshop}

De studenten van de vijf afstudeerrichtingen werden onderverdeeld in zes groepen van vijftig studenten. De studenten werden bij aanvang van de workshop ook ingedeeld in multiprofessionele groepen van tien studenten, twee van elke studierichting. De studenten bekeken samen een video-opname van een bejaarde vrouw die vertelt over haar situatie. Vervolgens formuleerden de studenten per studierichting drie vragen die ze aan deze vrouw zouden willen stellen. Nadien kregen ze in de multiprofessionele groep van tien studenten de opdracht een zorgplan op te stellen voor deze vrouw. Na afloop beoordeelden zij het overleg in de multiprofessionele groep en werden de bevindingen in de voltallige groep besproken. Elke groep van tien studenten werd geobserveerd door een docent.

\section{Data-analyse}

Er is een factoranalyse uitgevoerd om na te gaan welke items bij elkaar horen. Met de samenhorende items werden schalen geconstrueerd waarvan de interne consistentie werd nagegaan aan de hand van Cronbachs alfa. Met behulp van variantieanalyse werden de verschillen tussen de scores van de diverse studentengroepen nagegaan.

\section{Resultaten}

\section{Respons}

253 studenten hebben voorafgaand aan de workshop de vertaalde RIPLS ingevuld. Dit betrof 57 (75\%) van de studenten geneeskunde, 34 (75\%) van de studenten kinesitherapie, 92 (92\%) van de studenten maatschappelijk werk en $70(80 \%)$ van de studenten verpleegkunde. De studenten ergotherapie hadden de vragenlijst voor- afgaand aan de workshop niet ingevuld en zijn daarom niet opgenomen in de vergelijkende resultaten. $\mathrm{Na}$ afloop van de workshop hebben 232 studenten de vragenlijst ingevuld. Dit betrof 45 (39\%) van de studenten geneeskunde, 30 (99\%) van de studenten ergotherapie, 42 (99\%) van de studenten kinesitherapie, 51 (51\%) van de studenten maatschappelijk werk en 64 (70\%) van de studenten verpleegkunde. De resultaten van de voor- en nameting konden niet op studentniveau worden gekoppeld.

\section{Factoranalyse (tabel 1)}

Op de 253 volledig ingevulde vragenlijsten die tijdens de voormeting verzameld werden, werd een factoranalyse uitgevoerd. Na varimaxrotatie kozen we voor een oplossing met twee factoren, omdat er te weinig items met voldoende hoge lading waren om een derde schaal te kunnen construeren. Bovendien was de samenhang moeilijk interpreteerbaar. De oplossing met twee factoren resulteerde in voldoende hoogladende items per schaal en was beter interpreteerbaar. Op basis daarvan werden twee schalen geconstrueerd. De eerste schaal bestond uit negen items met ladingen van .70 tot .42 en een interne consistentie (Cronbachs alfa) van .80. De tweede schaal bestond uit vijf items met een lading tussen .63 en .52 en een interne consistentie van .65. Vier items werden in geen van beide schalen opgenomen: drie omdat ze hoog laadden op beide schalen en één omdat het zeer laag laadde op beide schalen. Herhaling van de factoranalyse op de gegevens van de nameting leverde een vergelijkbare factorstructuur op. Daarom werden dezelfde schalen behouden bij de nameting. De interne consistentie bij de nameting was .80 voor de schaal van negen items en .48 voor de schaal van vijf items. 
Tabel 1. Items van de vertaalde RIPLS per schaal (2 schalen en 4 losse items) met ladingen van de factoranalyse bij voor-en nameting. De ladingen van de overeenkomstige items uit de oorspronkelijke RIPLS uit het onderzoek van Parsell en Bligh worden weergegeven met de verdeling van de items over schaal I-IIl en Cronbachs alfa voor elke schaal.?

Items

Vertaalde RIPLS Oorspronkelijke RIPLS

$\frac{\text { Lading }}{\text { Voor } \mathrm{Na}} \frac{\text { Schaal en lading per item }}{\mathrm{I}(0.88) \text { II (0.63) III (0.32) }}$

Schaal 1. Effectiviteit en samenwerking

Door samen met studenten van andere zorgdisciplines

in een kleine groep een casus te bespreken:

6. zal ik beter in staat zijn het probleem van een patiën te verhelderen.

1. zal ik een meer effectief lid van het zorgteam worden.

5. zal ik een beter teamlid worden.

2. zal ik beter leren communiceren met patiënten en andere gezondheidswerkers.

3. zal ik klinische problemen beter leren begrijpen en onderkennen.

8. zal ik eigen beperkingen ontdekken.

7. zal ik een positief beeld over andere zorgverstrekkers kriigen.

9. Ik vind het een goed idee met andere zorgdisciplines in kleine groepen samen te zitten.

12. Studenten moeten elkaar vertrouwen en respecteren om in een kleine groep te kunnen samenwerken.

$\begin{array}{llll}0.70 & 0.76 & & -0.43 \\ & & & \\ 0.68 & 0.45 & 0.79 & \\ 0.67 & 0.74 & & -0.41 \\ 0.62 & 0.65 & & -0.54 \\ & & & \\ 0.54 & 0.62 & 0.77 & \\ & & & \\ 0.51 & 0.53 & 0.44 & \\ 0.50 & 0.41 & 0.68 & \\ & & & \\ 0.49 & 0.64 & & -0.44 \\ & & & \\ 0.42 & 0.65 & 0.66 & \\ & & & \end{array}$

Schaal II. Professionele identiteit

16. Een arts moet veel meer kennis en vaardigheden

aanleren dan studenten van andere zorgdisciplines.

15. Verpleegkundigen en andere paramedici moeten in de eerste plaats de arts ondersteunen in zijn werk.

17. Mezelf bekwamen in het oplossen van klinische problemen kan enkel met studenten van mijn eigen discipline.

11. Studenten van zorgverlenende beroepen moeten leren samenwerken in een team.

14. Samen opleiding volgen met studenten van andere zorg disciplines is overbodig. worden samen met studenten van andere zorgdisciplines.

4. Door samen met studenten van andere zorgdisciplines in een kleine groep een casus te bespreken voor ik afstudeer, zullen mijn relaties met anderen in mijn latere praktijk positief beïnvloed worden.

13. Patiënten worden er beter van als studenten uit de gezondheidszorg leren samenwerken om een probleem op te lossen.

18. Ik voel mij onzeker over mijn professionele rol. 
Schaal 1. Effectiviteit en samenwerking (9 items)

Deze schaal bevat stellingen met de strekking dat de student door gezamenlijk onderwijs met studenten van andere gezondheidszorgopleidingen een betere, effectievere hulpverlener zal worden. Zes items vroegen naar de verwachting van verhoogde effectiviteit als resultaat van de MPO-workshop. Het hoogst ladende item van deze schaal is: "Door samen met studenten van andere zorgdisciplines in een kleine groep een casus te bespreken, zal ik beter in staat zijn het probleem van een patiënt te analyseren" (lading .70). Ook in de meeste andere items herkent men de verwachting van toegenomen effectiviteit door MPO. De drie laagst ladende items van deze schaal (.42 tot .50) benadrukken het belang van een positieve attitude ten aanzien van andere disciplines als voorwaarde om een effectievere samenwerking te realiseren.

\section{Schaal 2. Professionele identiteit (5 items)}

Deze schaal bestaat uit stellingen over de verhouding en de verschillen tussen de diverse disciplines. Een hoge score geeft aan dat veel waarde wordt gehecht aan het eigene van de betrokken disciplines en duidt op een negatieve houding ten aanzien van samenwerking. Hoog ladende items zijn bijvoorbeeld item 16: "Een arts moet veel meer kennis en vaardigheden aanleren dan studenten van andere zorgdisciplines" (lading .64) en item 15: "Verpleegkundigen en andere paramedici moeten in de eerste plaats de arts ondersteunen in zijn werk" (lading .63).

\section{Vergelijking tussen de subgroepen (figuur 1)}

Wat betreft de variabelen leeftijd en geslacht werden geen significante verschillen gevonden.
Variantieanalyse van de gegevens van de voormeting liet geen significante verschillen zien op de schaal 'Effectiviteit en samenwerking'. Op de schaal 'Professionele identiteit' scoorden de artsen en kinesisten significant hoger dan de maatschappelijk werkers en verpleegkundigen ( $\mathrm{F}=19.58, \mathrm{p}<.0001)$.

Bij de nameting was er een significant verschil op de schaal 'Professionele identiteit' $(\mathrm{F}=7.26, \mathrm{p}<.0001)$, waarbij de verpleegkundigen het laagst scoorden (9.78) en de artsen het hoogst. Op de schaal 'Effectiviteit en samenwerking' was er bij de nameting eveneens een significant verschil $(\mathrm{F}=4.80, \mathrm{p}<.001)$. Er zijn vooral verschillen tussen de maatschappelijk werkers (31.7) en de verpleegkundigen (35.5).

\section{Vergelijking tussen voor-en nameting}

Voor de volledige onderzoeksgroep is er een significant verschil tussen voor- en nameting voor de schaal 'Effectiviteit en samenwerking' $(\mathrm{t}=2.56, \mathrm{p}<.01)$. Het gemiddelde ligt hoger bij de nameting: Alle deelnemers voelden zich gemiddeld effectiever als zorgverlener.

Voor de variabele studierichting meten zowel de schaal 'Effectiviteit en samenwerking' $(\mathrm{F}=4.34, \mathrm{p}<.0002)$ als de schaal 'Professionele identiteit' ( $\mathrm{F}=5.09, \mathrm{p}<.0001)$ een significant verschil.Voor de eerste schaal zijn de gemiddelde scores van de artsen, kinesisten en verpleegkundigen bij de nameting gestegen, terwijl die van de maatschappelijk werkers zijn gedaald. De laatsten hebben het gevoel minder effectief in de samenwerking te zijn geworden. Voor de schaal 'Professionele identiteit' valt vooral op dat de scores van de kinesisten en de verpleegkundigen dalen, terwijl de score van de maatschappelijk werkers stijgt (figuur 1). 
Figuur 1. Scores bij voor- en nameting van de verschillende groepen studenten op de schaal 'Effectiviteit en samenwerking' en de schaal 'Professionele identiteit'.

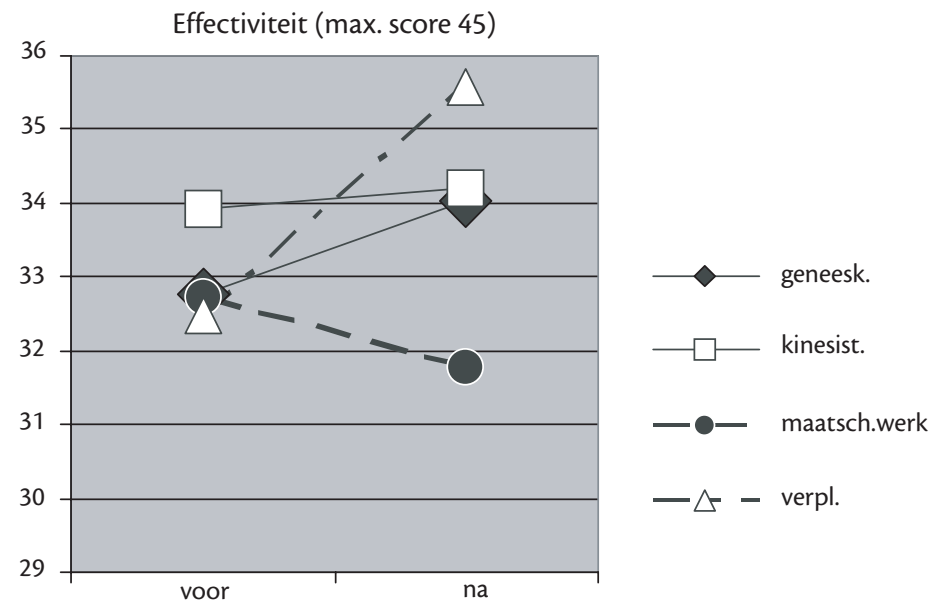

Professionele identiteit (max. score 25)

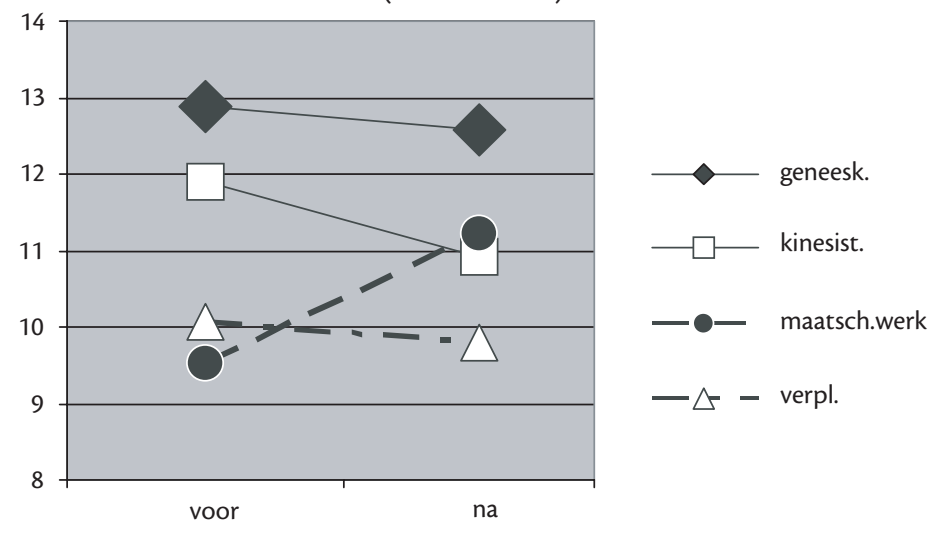

Vergelijking met de resultaten van de factoranalyse op de oorspronkelijke RIPLS (tabel 1)

Uit onze factoranalyse kwam een oplossing met twee factoren als beste naar voren, waar Parsell en Bligh er in hun analyse van de RIPLS drie behielden. De eerste twee dimensies die wij vonden, kwamen inhoudelijk goed overeen met de eerste twee die zij benoemden (tabel 1).
Er zijn vijf items die bij beide analyses in de eerste schaal terechtkomen, waarvan er drie bij de hoogst ladende zijn. Andere items behoren tot verschillende schalen. Een opvallend voorbeeld hiervan is item 6 , dat in onze analyse het hoogst laadt op de schaal 'Effectiviteit en samenwerking', terwijl het bij Parsell en Bligh tot de tweede schaal behoort. De tweede schaal in ons onderzoek lijkt een samenvoeging 
van de derde schaal van Parsell en Bligh met twee items van hun tweede schaal.

\section{De mening van de studenten over de workshop (figuur 2)}

De studenten waren over het algemeen erg tevreden over de workshop. $88 \%$ van de studenten vindt het noodzakelijk dat MPO wordt opgenomen in de basisopleiding. $82 \%$ van de studenten geeft aan dat hun inzicht over de rollen en de taken van anderen vergroot werd door deze ervaring en $80 \%$ zegt dat deze ervaring de toekomstige professionele relaties heeft beïnvloed. De verschillen tussen de groepen zijn te vinden in figuur 2. $61 \%$ van de studenten antwoordde bevestigend op de vraag: "Heeft deze workshop je inzicht in het werk van andere gezondheidswerkers veranderd?" en 43\% antwoordde met ja op de vraag" Heeft deze workshop je attitude ten aanzien van andere gezondheidswerkers veranderd?" Er werden geen significante verschillen vastgesteld tussen de studierichtingen.

\section{Discussie}

De vertaalde vragenlijst blijkt in de Vlaamse cultuur anders te werken dan de oorspronkelijke Engelse vragenlijst. Vanuit louter linguïstisch oogpunt gaat het om dezelfde items, maar blijkbaar wordt er door de twee taalgroepen een andere betekenis aan gegeven. Daar kunnen tal van oorzaken voor zijn. Zoals opgemerkt,

Figuur 2. Meningen van de studenten na afloop van de workshop. Percentage studenten per beroepsgroep dat bevestigend antwoordde op vraag 1 tot en met 5 van de enquête.

\section{Vragen:}

Heeft deze workshop:

1. je kennis vergroot over de rollen en taken van anderen?

2. je inzicht over het werk van anderen veranderd?

3. je attitude ten aanzien van andere gezondheidswerkers veranderd?

4. Heb je het gevoel dat een MPO-workshop effect zal hebben op je toekomstige relatie met andere zorgverstrekkers?

5. Moet MPO opgenomen worden in het lessenpakket van de basisopleiding?

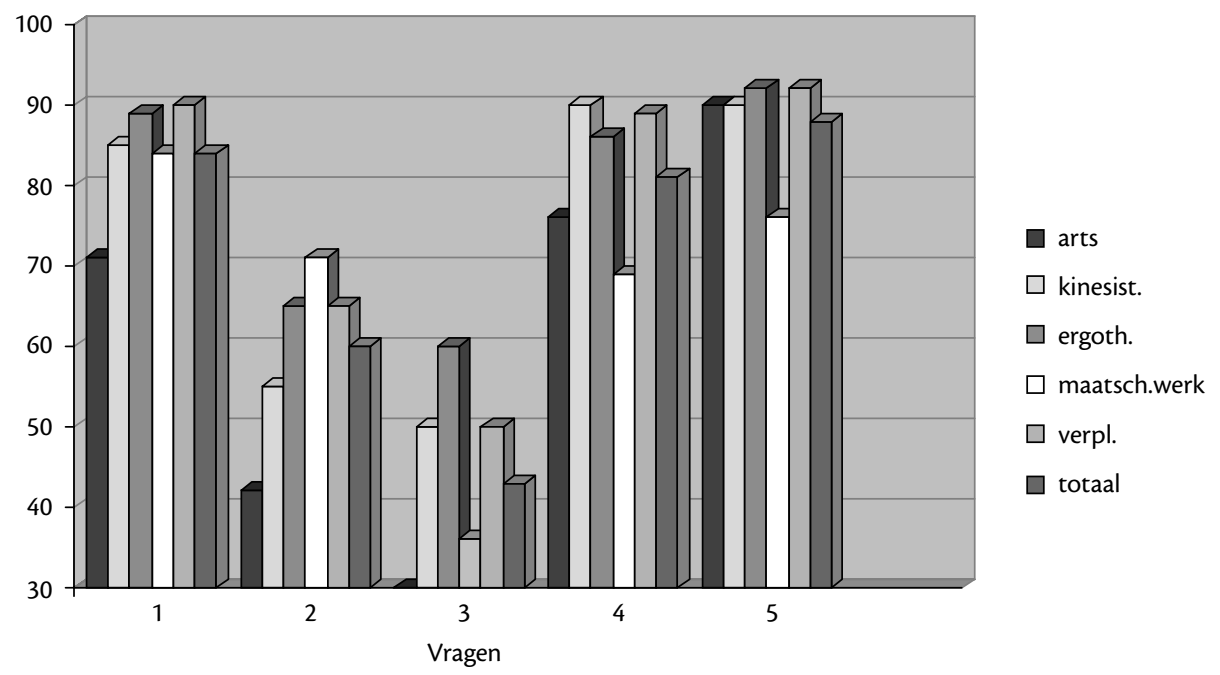


bleek achteraf dat er in de vertaling een item vergeten was. Het effect daarvan is vermoedelijk niet zo groot. Wellicht spelen vertaalproblemen ook nog een rol. Ook bleek dat de betrouwbaarheid van de tweede schaal onstabiel was. Cronbachs alfa was in de voormeting .60 en in de nameting .48.

Het was mogelijk om met de vragenlijst verschillen op de schaal 'Effectiviteit en samenwerking' te meten. Het verschil tussen de voormeting (gemiddeld 33.4) en de nameting (gemiddeld 34.7) was significant. Studenten lijken inderdaad te verwachten dat het bespreken van een casus met studenten van andere zorgdisciplines hun effectiviteit zal verhogen. Ze verklaren zich bereid tot het volgen van MPO. De stijging van de gemiddelden na de workshop lijkt erop te wijzen dat hun verwachtingen ingelost werden. Dit wordt bevestigd door de scores van de studenten op de evaluatievragenlijst die na de workshop is afgenomen. Opvallend is dat de studenten maatschappelijk werk als enige discipline een lagere score behalen op deze dimensie bij de nameting.

Wat de gemiddelde scores op de schaal 'Professionele identiteit' betreft, is er geen significant verschil tussen de voor- en de nameting. De disciplines reageren wel geheel verschillend. De studenten maatschappelijk werk behalen als enige studierichting bij de nameting een hogere score op deze schaal.

\section{Conclusies en aanbevelingen}

De workshop werd positief beoordeeld en zal dan ook weer gegeven worden. Alle deelnemers voelen zich effectiever als zorgverlener na de workshop. De verschillen tussen de disciplines zijn interessant. De groep maatschappelijk werkers reageerde anders dan de andere groepen. Wellicht kan dit worden verklaard door- dat zij in het beleven van de studenten anders zijn dan de andere groepen.

Een belangrijke kanttekening die nog gemaakt moet worden, is dat het slechts een korte workshop over MPO betrof. Het is mogelijk dat een langere cursus andere effecten veroorzaakt. Ons inziens is het dan ook gewenst om daar verder onderzoek naar te doen. Ook verdient het aanbeveling om de oorzaken van de verschillen tussen de Engelse RIPLS en de Nederlandse vertaling aan een nader onderzoek te onderwerpen.

\section{Literatuur}

1. Gray P, Goble REA. The case for multiprofessional practice. Unpublished Position Paper. Exeter: University of Exeter; 1998.

2. Mackay L. Conflicts in care: medicine and nursing. London: Chapman \& Hall; 1993.

3. Ridder D de. Communicatie tussen huisartsen en thuisverpleegkundigen. Kontakt 1994.

4. Verbeek-Weel AAM, Metz JCM. Multiprofessioneel onderwijs: een haalbaarheidsonderzoek. Tijdschrift voor Medisch Onderwijs 2001;20(4): 140-6.

5. Horsburgh M, Lamdin R, Williamson E. Multiprofessional learning: the attitude of medical, nursing and pharmacy students to shared learning. Med Educ 2001;35:876-83.

6. Harden RM, Grant J, Buckley G, Hart IR. BEME guide no. 1: best evidence medical education. Med Teach 1999;21(6):553-62.

7. Parsell G, Bligh J. The development of a questionnaire to assess the readiness of health care students for interprofessional learning (RIPLS). Med Educ 1999;33:95-100.

De auteurs:

Lic. Chris Aubry, coördinator van het vaardigheidsonderwijs aan de Faculteit Geneeskunde van de Katholieke Universiteit Leuven.

Prof. dr. Jo Goedhuys, doctor in de psychologische wetenschappen $(P h D)$ en docent aan de Faculteit Geneeskunde van de Katholieke Universiteit Leuven.

Lic. Rob Stroobants, methodoloog aan de Faculteit Psychologie en Pedagogische Wetenschappen van de Katholieke Universiteit Leuven.

Correspondentieadres:

Chris Aubry, Vaardigheidscentrum Faculteit Geneeskunde KUL, Kapucijnenvoer 33, 3000 Leuven, Chris. Aubry@med.kuleuven.ac.be. 


\section{Summary}

Purpose: Multiprofessional education (MPE) can be a good preparation for teamwork for future health care professionals. We evaluated whether a Dutch translation of the Readiness for Interprofessional Learning Scale (RIPLS) was suitable to evaluate a multiprofessional workshop for Belgian students.

Methods: Final-year students training to become doctors, nurses, social workers, physiotherapists and occupational therapists, respectively, were asked to complete the RIPLS before and after participating in a multiprofessional workshop. They also completed a brief questionnaire about the workshop. Factor analysis was performed to determine the internal consistency of the RIPLS. Analysis of variance was performed to analyse the differences between student groups.

Results: Factor analysis yielded two scales: 'Future professional efficiency' and 'Professional identity' with Cronbach's alpha of .80 and .60, respectively. The post-test showed higher scores on 'Professional efficiency' compared with the pre-test. The reliabilities of the dimension 'Professional identity' differed between pre-test and post-test. Student groups differed in their attitude toward MPE. The short questionnaire showed a positive appreciation of the workshop.

Discussion: Comparison between the original RIPLS and the translated Dutch version showed differences and similarities. The reliability of the dimension professional identity differed between pre-test and post-test.

Conclusion and recommendations: The results suggest a positive effect of a short MPE workshop. It would be interesting to investigate the effects of a more extensive course. Although the findings of the Dutch RIPLS were supported by the short questionnaire, the reliability of the Dutch RIPLS should be investigated further. (Aubry C, Goedhuys R, Stroobants R. Evaluation of multiprofessional education using the Readiness for InterProfessional Learning Scale (RIPLS). Dutch Journal of Medical Education 2003;22(3):106-114.) 